\title{
Diálogo interreligioso y diapraxis
}

\author{
José Ignacio González Faus, \\ San Cugat del Vallés, Barcelona, \\ Centro de Reflexión Teológica, \\ San Salvador.
}

"Para que sean hijos de su Padre que está en los cielos, que hace salir el sol sobre cristianos y no cristianos". Las religiones se encontrarán hacia fuera, no hacia dentro.

1. Del diálogo a la "diapraxis" por la paz, la justicia y la integridad de la creación

Los exegetas están bastante de acuerdo en que una de las palabras que más reflejan la experiencia del Dios de Jesús es aquella frase de san Mateo en que Jesús ordena amar a los "enemigos", no por un principio de perfección ética, sino "para que sean hijos de su Padre que está en los Cielos, que hace crecer su pan material para ricos y pobres, y parte su pan eucarístico para cristianos y no cristianos" (si se me permite la paráfrasis de Mt 5,45 ).

Desde esta óplica cabe una cierta sospecha de que el problema de las religiones de la tierra no esté siendo correctamente planteado. En efecto.

Una cosa es qué dice sobre las otras religiones la reflexión (o la teología) de cada una de ellas. Lo cual puede ser un problema meramente interno, que a algunas religiones quizá ni les interese.

Pero otra cosa muy distinta es cómo las religiones viven y conviven en este planeta. Esta segunda cuestión es mucho más importante y urgente que la anterior, aunque, sin duda, la respuesta que se dé a aquélla no dejará de afectar a ésta.

\subsection{Un díálogo sin praxis común es estéril}

Antes de plantear el problema no vendrá mal recordar que quienes lo tenemos planteado somos seres humanos, no dioses, ni ángeles. Ahora bien, pertene- 
ce a lo más hondo de nuestra condición humana el que las cosas que más nos unen suelen ser también las que más nos separan. Por ejernplo, las palabras comunes pueden crear comunidad y odios, los cuerpos pueden activar amor y abuso, las banderas provocan entusiasmo colectivo y guerras, las experiencias religiosas pucden dar lugar a iglesias y a sectas... Debe ser consecuencia inevitable de nuestra condición de divinos y no divinos (imágenes aulénticas de Dios y meras creaturas empecatadas).

Entre las cosas que más nos unen y más nos separan están las palabras. Este es el contexto antropológico en el cual se plantea el problema de las diversas corrientes religiosas del planela. Por eso, no me siento cómodo cuando se dice que la tarea aclual de las religiones es el diálogo, como si se tratara de sentar a unos cuantos expertos en torno a una mesa a ver si se ponen de acuerdo en algo. Aun en el caso de que lograran ponerse de acuerdo en algo (en lugar de pelearse, que sería lo más probable, si creen de veras en lo que dicen creer), aun en ese caso ideal, habría que recordar que las religiones no son sus fórmulas, ni sus experlos, ni sus ulemas, ni sus shaniasis, ni sus curas, sino sus fieles (a los cuales también pertenecen los curas y los teólogos).

Sospecho que antes del diálogo interreligioso debería venir la vida en común, la lucha en común, la oración en común, y que cada religión debe preguntar a sus tradiciones fundacionales si le facilitan eso y cómo. La vida en común para aprender a respetarse, la lucha en común, que enseña a quererse, y la oración en común, que crea confianza mutua. La vida en común, además, dará lugar a muchos momentos de fricción, que pedirán un diálogo sobre temas profanos (como en estos momentos está ocurriendo en España con la cuestión de si las niñas árabes pueden acudir con velo a la escuela). Y sólo cuando la convivencia y la lucha en común hayan madurado, tendrá senlido hablar de diálogo interreligioso.

Para el caso cristiano, el texto de Mateo que he citado al comienzo me parece fundamental. Sólo entonces, el diálogo será diálogo y no una yuxtaposición de monólogos incomprensibles. Entendido desde esa frase de Jesús en san Mateo, el diálogo entre las religiones tendría que comenzar encontrándose no para argumentar sobre sus dogmas, sino para ver cómo contribuyen entre todas a más paz y más justicia, en el mundo. Lo otro, como decía Jesús, "vendrá por añadidura".

Un ejemplo bien claro de esa forma de diálogo sería ponerse todas de acuerdo para exigir a los gobiemos de los países donde tienen más implantación determinadas políticas de tipo armamentista, económico, ecológico, etc. Sobre eso es de lo que habría que dialogar, como decía Jesús: "esto es lo que hay que hacer, aunque sin olvidar lo otro". Al final de esta nota contaré una parábola, que puede ejemplificar esa gran tarea "diapráxica". 


\subsection{Hacia fuera y hacia dentro}

La praxis conjunta y la convivencia afectuosa deben suplir las mil ambigüedades de la mera palabra, que señalábamos al comienzo. Ambigüedades que, por si fuera poco, no se dan sólo hacia luera. También se dan hacia dentro, y pueden tener efeclos negativos al interior de la comunidad misma de fe, donde también andamos hoy necesilados de grandes dosis de ecumenismo.

Por ejemplo, al interior de la comunidad de fe, el diálogo interreligioso que intentamos emprender podría separarnos, a través de las esiquetas con que dividimos a los que se ocupan del problema de las religiones. De hecho, ya nos hemos acostumbrado a calificar y clasificar a los que andan en eso de las religiones de la tierra. Y las calificaciones pueden ser útiles para clarificar cuestiones, pero es sabido cuántas veces entre los humanos, calificar es una forma "políticamente correcta" de descalificar.

Así, cualquier escrito sobre el tema de las religiones repile hoy una división parecida a ésa de "exclusivistas, inclusivistas y pluralistas" (con todas las subdivisiones que se le quieran añadir), y encasilla en esa división todas las demás opiniones. Y en este ejercicio, el lérmino "división" manifiesta en acto la ambigüedad de cualquier palabra humana: es un término que debería significar ordenamiento, y acaba significando separación. El que está en una de esas posiciones considera inaceptables a los que están en las otras, elc. Por ejemplo, los exclusivistas son simplemente intolerantes, los pluralistas traicionan la identidad cristiana, etc.

$Y$ no diré que no haya algo de razón en ese modo de reaccionar ante nuestras divisiones, porque no hay nada entre nosotros que no sea limitado, y no hay límite que no pueda ser a veces peligroso. Pero sumándome a las últimas voces que consideran como superada esa división (exclusivismo, inclusivismo y pluralismo), creo que la fe cristiana se situaría mejor ante las religiones, si se preguntara en qué tiene que ser exclusivista, en qué tiene que ser inclusivista y en qué pluralista. Porque es probable que cada una de las tres pueda tener su parte de verdad. ( $Y$ he dicho "la fe cristiana" no sólo porque yo soy cristiano, sino porque me parece también que es al cristianismo a quien las demás religiones de la tierra le plantean mayores problemas teológicos).

Pues bien, desde esta óptica cristiana, que parece ser aquella en la que Dios me ha querido, y tratando de ejercitar el consejo de Jesús, citado al comienzo, creo que las cartas paulinas llamadas "de la cautividad" suministran importantes elementos de reflexión para nuestro problema.

Digo que son elementos de reflexión y no de respuesta, porque en tiempos de Pablo, no existía el planteamiento actual. Desde esas cartas se puede afirmar que en el cristianismo hay, a la vez, elementos exclusivistas, inclusivistas y pluralistas. Y que la Gracia consiste en saber mantener los tres, cada cual en su sitio, pero sin que ninguno esté ausente, ni tampoco invada a los demás. 
Y por tanto, para amar a los de fuera y ser así con ellos "hijos de un mismo Padre que hace nacer Su sol sobre todos nosotros", sospecho que el cristiano debería ser exclusivista en la cruz, inclusivista en la resurrección y pluralista en la lglesia.

\subsection{Qué exclusivismo}

El cristianismo liene una única verdad irrenunciable: la del salvador crucificado. Es conocido cómo la obsesión de san Pablo, precisamente, el apóstol de la libertad cristiana, fue "no vaciar la cruz de Cristo" (1Cor 1, 17). Ese ha sido siempre el peligro de todas las iglesias: vaciarla o, lo que es mucho peor, desfigurarla o utilizar la cruz como arma propia para el sometimiento de los demás.

Hay, en mi opinión, un exclusivismo de la cruz, que se insinúa, por ejemplo, en la frase del himno de Colosenses $(1,20)$ : "hizo la paz con todas las cosas por la sangre de su cruz". La paz entre las religiones brola, para un cristiano, de la cruz de Jesucristo, y sin ésta, no puede haber tal paz. Entre otras razones porque (sin negar la culpa del "pagano" Pilatos), el cristiano sabe que los que crucificaron a Jesús fueron "los suyos", no los de fuera. Esto lo obliga a ir al encuentro de las religiones, sintiéndose más pecudor y más responsable ante el Crucificado que sus interloculores. Por eso la Cruz es irrenunciable, y el cristiano es "exclusivista", en este punto.

También por eso, en la convivencia con las religiones, el cristiano deberá decir ( $i$ y ejercitar!) que él cree en un Dios crucificado, "anonadado", vaciado por amor a la humanidad de su poder, despojado de "su condición divina" al relacionarse con nosotros, como modo de identifícación con lodos los crucificados de la tierra, y aunque esa identificación pueda suponer una nueva "sangre de cruz" para el cristiano.

Este no será un elemento que "se imponga", porque no se trata en él de un irrenunciable "reivindicativo" (como si se tratara, por ejemplo, de la capitalidad de Jerusalén para árabes y judíos). Será sólo un elemento del cual el cristiano afirmará que él no puede abandonarlo, ni olvidarlo. Pero que, precisamente, ese elemento le impide estar en guerra con ninguna religión. Y de hecho, los que en el campo de las religiones adoptan posturas menos ecuménicas, suelen predicar un cristianismo muy "razonable" y muy poco "crucificado"'.

\subsection{Qué inclusivismo}

El cristianismo, además, es inclusivista, en lo que loca a la resurrección. Porque el cristianismo no cree en la resurrección de sólo Jesús, sino en que esa

1. En octubre del 2001 publiqué, en la prensa, un artículo sobre el documento del "santo oficio" relativo al cristianismo y las demás religiones, que se titulaba, precisamenic, "La cruz de la Dominus lesus". 
resurrección incluye y comporta la de toda la humanidad. "Resucitando a Jesús, Dios recapiluló en El todas las cosas", y ésta es "la obra realizada por Dios con despliegue de su poder, y predestinada desde antes de los tiempos» (cfr. Ef 1,20 y 10). El cristiano no puede esperar para sí la resurrección y excluir de esa esperanza a los demás creyentes de otras religiones: sólo puede esperar la resurrección para todos los seres humanos, porque Jesucristo resucitó como "primicia de los que murieron" ( 1 Cor 15,20$)$ y "primogénito de entre los muertos" (Col 1, 18).

Esta forma de inclusivismo tampoco invade ni domina el campo de las demás religiones. No les dice que son cristianas, aunque no quieran, sino que son "resucitadas". Esa fue la razón para que, en la antigüedad, «se derribase el muro" (Ef 2, 14) que separaba a las religiones más enfrentadas. El muro se derrumba, porque al encontrarse con cualquier ser humano, el cristiano sabe que se encuentra con alguien que ha sido "resucitado con Cristo y sentado en los cielos" (Ef 2, 6), como él.

"Eslo vale para todos" enseñó el Vaticano II, a propósilo de la pascua (GS 22). Pero además, para el cristiano que cree en Jesucristo resucitado, esa fe implica Iratar de vivir, ya ahora, como resucitado. Lo cual parece incluir la necesidad de comportarse ante los otros con esa novedad de relaciones que caracteriza a la resurrección y que Pablo calificaba como "cuerpo espiritual", donde el "cuerpo" hace alusión a la relación, y el "Espíritu" libera a esa relación de convertirse en una relación meramente particularista. Tratar a los otros como un resucitado y mirarlos como a quienes también "han resucitado con Crislo".

\subsection{Qué pluralismo}

Esto, precisamente, es lo que, además, vuelve al cristiano seria y serenamente pluralista, en su contacto con las otras religiones de la tierra: el resucitado es "cabeza de lodos" y, por tanto, me sale al encuentro, en todos.

Este encuentro con el crucificado-resucitado pone un punto final a toda visión de la evangelización como proselitismo. El proselitismo intenta, sobre lodo, acrecentar el número de prosélitos, eliminando la libertad del oyente. La evangelización, sin embargo, se dirige a la libertad del oyenle, y sólo intenta, por un lado, hacer presente la buena noticia del reinado de Dios cercano y de la resurrección de Jesús. Y, por otro lado, revestir al cristianismo de la came de todas las culturas, por su inmersión en ellas, para que el don de Dios a los seres humanos alcance todas las virtualidades de humanidad, que están incluidas en él.

Tanto la Carta a los Efesios como la de los Colosenses sorprenden, porque parecen afirmar que, siendo Cristo cabeza absolutamente de todo, sólo la Iglesia es su cuerpo. Ello quiere decir que la Iglesia no es cabeza de nada, sino sólo la llamada a conservar esa capilalidad de Crislo resucitado sobre todo. Y aquí puede estar el verdadero fundamento del pluralismo de las religiones. Si esa 
capitalidad ha sido confiada a la Iglesia, es sólo en la medida en que la Iglesia es (y para que sea) "la plenificación de un Cristo que se plenifica en todas las cosas" (Ef 1, 23). Ella no existe para sí misma, sino para los seres humanos, para el reino. Y su misión no consiste en aumentar su número y su poder, sino en que crezca en Ioda persona la calidad de lo que es humano, según Dios.

Naluralmente, eso se podría hacer por la entrada en la Iglesia de todos los seres humanos, pero no necesariamente ha de hacerse asi. Y de hecho, según algunos historiadores, las épocas de cristiandad no fueron precisamente las épocas más "cristianas". Pero ni la cristiandad (explícita o implícila), ni la búsqueda de ella son la única forma posible de que la Iglesia ejerza su misión. Sazonar lo humano, iluminar lo humano, Cermentar lo humano para que brote en la humanidad esa semilla mínima, pero capaz de crecer al máximo, como la del grano de mostaza, son todas ellas fómulas evangélicas, que hoy definen la misión del cristianismo mucho mejor que la fórmula de la cristiandad y que las noslalgias por una nueva cristiandad, que son las únicas calegorías en las cuales saben pensar algunos pastores.

La Iglesia sabe (o debería saber) que en cada persona, en cada familia, en cada cultura, en cada religión, le sale al encuentro su Señor. Infinidad de cosas del Antiguo Testamento, que hoy calificamos (con no demasiados matices) como "palabra de Dios", las aprendió Israel de los pueblos y las religiones vecinas, que fueron, por tanto, el camino elegido por Dios para revelar aquello a Israel. Las aprendió enriqueciéndolas muchas veces y matizándolas, o hasta mejorándolas. Pero las recibió de las otras religiones. Y sólo a través de ellas las recibió de Dios.

Y esto ha de valer mucho más hoy, cuando la universalidad de la elección de Dios ya no es una mera promesa (como en el tiempo de Israel), sino que ha sido realizada, en la resurrección de Jesucristo. Si se me permite un ejemplo, la pasión por la justicia y la opción por los pobres que hoy dan identidad a lo mejor del cristianismo actual, son enormemente cristianas. Pero será difícil negar que -históricamente hablando- el cristianismo de hoy las aprendió y las recuperó de aquella "religión" que fue el marxismo, por pasado y denostado que hoy se lo considere. Es así como Dios dirigió (y sigue dirigiendo hoy) la hisıoria de su pueblo.

Lo exclusivista del cristianismo, que son los crucificados de la tierra recapitulados en la cruz de Jesús, más lo inclusivista del cristianismo, que es la inclusión de todos en la resurrección de Jesús, más lo pluralista del cristianismo, que es la posibilidad de revelación de Dios, a través de todas las religiones de la tierra, vuelven a reorientar el tema de las religiones, no hacia mesas de diálogo para intelectuales (por necesarias que éstas sean: ¡que lo son, pero a su tiempo!), sino hacia ese trabajo por la paz que hace a sus promotores "hijos de Dios" (Mt 5,9 ), por los pobres, que son los "señores del reino de Dios" (Mt 5, 3), y por el respeto a la creación, que es el único que nos hará "poseer la tierra" (Mt 5, 5). 
Para ilustrar lo dicho se puede poner un ejemplo, en forma de parábola, de esa tarea que hoy debería ser común a todas las religiones: el trabajo conjunto por la justicia, en un mundo tan injusto, por la paz, en un mundo san cruel, por la tierra tantas veces violado por el hombre, y por la verdad humana, en un mundo que, además, enmascara su inhumanidad, tratando de hacernos creer que es el mejor que ha existido nunca (creencia que, por supuesto, será tenida como una gran verdad para aquellos que así hablan y que son una minoría de personas con una mayoría de poder, pero no lo es para la gran mayoría del género humano).

Ese trabajo conjunto tiene mucho que ver con lo que los obispos norleamericanos llamaron "Justicia económica para todos". Porque sin justicia económica no podrá haber, a la larga, ni democracia, ni paz o convivencia pacífica, ni salvaguarda del planeta. Por eso, vamos a contar ahora una parábola sobre la economía mundial.

\section{Parábola de la economía mundial}

Dialogaban un teólogo cristiano, que enseñaba en Roma, y otro musulmán. El cristiano, conociendo el respeto y la literalidad con que los musulmanes leen los textos sagrados, le presentó la narración del capítulo 8 de san Marcos, que relata cómo Jesús sentía conmovidas las entrañas por tanta gente que no podía comer nada, y acabó la escena con una "multiplicación de los panes y los peces". Y el teólogo argumentaba así a su interlocutor:

- Aqui tienes una de las mayores pruebas de la divinidad de Jesús, y de la encarnación en la cual ustedes no quieren creer. Pues, al multiplicar los panes, Jesús "creó de la nada", cosa que sólo Dios puede hacer. $Y$ encima, hasla exegetas críticos de esos que no respetan la Biblia, como ese esladounidensc, llamado J. Meier, llegan a la conclusión de que "debajo de este pasaje hay 'algo' ocurrido en la vida de Jesús". ¡Hasta ellos tienen que reconocerlo!

- Pues no me convence nada, replicó el musulmán. Y hasta estoy seguro de que el Vaticano de ustedes no aceptaría eso como un "milagro", si examinara los hechos de Jesús con el mismo rigor con que examina los de Lourdes.

- ¿Cómo que no lo aceptaría? ¡Si está en la Biblia!

- Pero si Jesús quería crear de la nada, lo que tenía que haber hecho es prescindir de los panes y los peces, y decir simplemente: "hágase el pan", y que el pan se hubiera hecho. Alá no necesitó de la pequeña sabiduría de los hombres para dictar el Corán: no lo escribió aprovechando cinco páginas y dos notas que tenía escritas Mahoma. Simplemente lo dictó desde el cielo. Mientras que en el ejemplo que me pones, habiendo una materia previa, siempre queda una sospecha, que impide decir con absoluta seguridad que se trató de una creación de la nada. ¡Seguro que si tuviera que "canonizar" a Jesús, la Iglesia de ustedes no aceptaría ese milagro! 
El teólogo estuvo a punto de decirle que él, que vivía en Roma, sabía que hoy, cuando interesa, pasan muchas cosas dudosas por auténticos milagros. Pero prefirió callárselo para no escandalizar al musulmán. Prefirió decirle que, bueno, él era dogmático y no biblista. Pero que ese punto podría estudiarse más despacio con exegetas acreditados...

Por una de esas casualidades de la vida, al llegar al convento en que vivía el profesor se encontró (como pasa tantas veces en Roma) con que estaba hospedado allí un grupo de una comunidad de base del tercer mundo, de las que se decía que estaban en Roma no se sabe si peregrinando, o para ser examinados por el Santo Oficio. Coincidieron a la hora de cenar, y él aprovechó para contarles todo lo que le había ocurrido con el musulmán, y para adocırinarlos así sobre el peligro que supone que gentes inexpertas se melan a explicar la Biblia, pues pueden acabar diciendo barbaridades como las de aquel infiel. Esperaba que asi aprenderían a no correr riesgos inútiles y malos para la ortodoxia calólica.

Pero alguien de la comunidad le preguntó: ban?

- Monseñor, y ¿por qué no seguimos leyendo el texlo que ustedes comenta-

- $\mathrm{Y}$, ¿qué es eso que tenemos que seguir leyendo? -preguntó el teólogo con el aire de quien sabe que ya lo ha leído todo.

- Simplemente lo que dice el texto evangélico a que usted se ha referido. Cuando los hombres le piden a Jesús que dé de comer a las multitudes hambrientas, El se limita a decir. "denles ustedes de comer". ¿No?

- Claro. Pero eso era para demostrarles que ellos no podían y El sí, porque era Dios.

- Quizá no, monseñor. A lo mejor es que ésa es siempre la respuesta de Dios, cuando le pedimos según qué cosas: "háganlo usledes".

- Perdonen. Pero son ustedes unos ignorantes, si es que creen de veras que Dios todopoderoso es el que pide milagros a los hombres, en lugar de pedírselos nosotros a El.

- Por supuesto que somos bien ignorantes, monseñor. Pero como en este momento no tenemos ninguna Biblia a mano, ihará usted el favor de leernos cómo sigue el pasaje evangélico? Usted conoce la lengua original y podrá traducímoslo mejor.

- Con mucho gusto. Marcos cuenta que los discípulos respondieron: "Con un dineral no bastaría para dar de comer a tantísimas gentes. Además, tendríamos que ir lejos a comprar el pan".

Al oír lo de comprar el pan, intervino un conocido sindicalista del partido de los trabajadores, que era miembro de aquella comunidad: 
- Esa respuesla se parece a lo que dijeron los señores de Davos reunidos en Nueva York, entre grandes medidas de seguridad: que ellos ya quieren acabar con el hambre, pero para eso han de producir primero toda la riqueza necesaria. Por eso prometieron que hacia el año 2004 ya habrían acabado con la mitad del hambre del planeta. Pero ahora han dicho que esa promesa no podrá ser cumplida.

- Por eso, el mismo evangelio confirma que necesitamos los milagros de Dios. Y suerte que Jesucristo era Dios y puede hacer esos milagros, si se los pedimos - aclaró el teólogo romano.

- A lo mejor, monseñor, lo que quiere enseñar el evangelista es que ésa es la infalible respuesta de los hombres cuando Dios nos pide algo que tiene que ver con la justicia y la eliminación de la miseria y la injusticia: “¡Uy! Eso costaría un dineral y nos llevaría mucho tiempo".

- ¿Tú crees que el evangelio quiere enseñar eso? ¡El evangelio no se mete en política!

- Fijese monseñor, cada Jomingo, los católicos rezan en sus misas: "Oremos por los que tienen hambre y carecen de lo más elemental. Te lo pedimos, Señor". Y hay algún teólogo que dice que csa oración no sirve para nada, porque todo sigue igual. Sin embargo, si supiéramos escuchar, si que serviría. Pues, el Señor responde. i $Y$ vaya si responde! Cuando le pedimos por los que tiencn hambre nos dice: "denles ustedes de comer". Cuando pedimos por los que no tienen trabajo, ni vacaciones, nos responde "denles ustedes trabajo y vacaciones". Pero, en lugar de escuchar su respuesta, los fieles gritan rápidamente otra petición para que no se pueda oír al Señor. "Pidamos por los miles que están siendo asesinados en El Congo". "Denles ustedes la vida. Inténtalo", responde el Señor. Pero queda ensordecido por esa metralleta piadosa que clama: "Pidamos porque haya paz entre las religiones. Te lo pedimos Señor". Y el Señor sigue diciendo: "hagan ustedes esa paz". Pero no hay manera (o no hay ganas) de escuchar la respuesta del Señor.

El teólogo sospechó que aquella comunidad, además de la fama de marxista que lenía (sin duda, bien ganada), era toda ella muy pelagiana, y que debería adoctrinarla bien, en este punto lan delicado. Pero anles de entrar a saco con la gracia y las obras humanas, recordó que tenía que "hacerse simpático", porque les habían dicho en el Vaticano que eso era fundamental para la pastoral. Y se dirigió a los niños, hijos de algunos miembros de aquella comunidad, que parccían seguir alentos la conversación entre sus padres y el monseñor.

- ¿Qué les parece? ¿Lo entienden o se están aburriendo? ¿Quieren ir un rato a ver la tele?

Oscar Antonio, un muchachito, hijo de uno de ellos, que tenía más imaginación que santa Teresa, ya estaba viendo al Señor rodeado del G-7 y el G-8, más los presidentes del Fondo Monetario Internacional y del Banco Mundial y de la 
Organización Mundial del Comercio, a los que Jesús decía: "denles ustedes de comer". Y hasta le parecía oír claramente cómo ellos respondían:

- Eso costaría un dineral. Y además, antes tendríamos que crear todo ese dineral. Nuestros cálculos sólo llegaron a prever que podríamos disminuir el hambre del mundo en un 50 por ciento para el 2004. Pero ahí nos equivocamos.

Y, como ya no se podía aguantar, Oscar le preguntó al grupo:

- ¿Qué dirían ustedes en un caso así?

- Yo nada. Comentó alguien del grupo. Pero dile al padre que te enseñe el texio de Marcos, a ver si el Señor respondió algo.

De pronto se le abrieron a Oscar unos ojos tan risueños como los de los reyes magos, cuando volvieron a ver la estrella. Y gritó:

- Jesús preguntó: ¿qué tienen usıedes? Jesús preguntó qué tienen. Y ellos comenzaron a responder:

- Cinco panes y dos peces. "Bien poca cosa" —completó el teólogo anticipándose.

- Y mintieron como bellacos, atacó Oscar Antonio. Deberían haber dicho que tenían una riqueza capaz de producir tantos cientos de misiles, tantos aviones de combate, tantos carros, tantas bombas de fragmentación, tantos proyectos de paraguas nucleares. Y capaz de gastar tres millones diarios de dólares para "defenderse de los hambrientos". Y entonces, Jesús les habría dicho: "les saldrá más baralo si le dicen a la gente que se siente y comienzan a distribuir bien". $i \mathrm{O}$ es que cree usted, monseñor, que todo eso no tiene nada que ver con la religión?

El papá de Oscar, que conocía muy bien a su hijo, y que ni con evangelio, ni con comunidad de base lograba inculcarle un poco de mansedumbre, que esperaba le ińa viniendo con la edad, prefirió poner término a la discusión, y le dijo al muchacho:

- A ver hijo: no hemos venido aquí a pelearnos con nadie. $Y$ como el padre tiene todavía que celebrar la eucaristía, será mejor que vayamos a celebrarla con él.

Se resistió Oscar, alegando que aquel día habian caminado demasiado entre coliseos y calacumbas, y que él estaba muy cansado. Pero el papá le recordó que más cansado debería estar Jesús después de andar varios días con la gente, y ello no le impidió preocuparse por ellos. Y que, precisamente, algo de eso es lo que iban a actualizar en la eucaristía.

Y quiso la casualidad que aquel día tocase un evangelio que el monseñor leyó con loda entonación en italiano, y permitió luego que fuese leído por un miembro de la comunidad en la lengua de ellos. El evangelio de aquel día decia, sencillamente:

— Jesús exultó de gozo exclamando: "Yo re bendigo Padre porque escondiste estas cosas de tu reino a los sabios y prudentes de este mundo, y las revelaste a los que el mundo desprecia". 